\title{
Desarrollo de las cláusulas contractuales y su fuerza vinculante en la contratación estatal en Colombia *
}

\section{Development of contractual clauses and their binding force in state contracting in Colombia}

\author{
Daniela Rivera García \\ Abogada, Especialista en Contratación Estatal y en \\ Derecho Administrativo y Constitucional, Colombia \\ daniela-rivera-garcia@hotmail.com \\ Francisco Javier Arias Benavides \\ Abogado, Especialista en Seguridad Social, Colombia \\ franariasbe@gmail.com
}

Recibido: 22/10/2018 Aprobado: 12/12/2018

DOI: $10.25054 / 16576799.2642$

\section{RESUMEN}

El presente trabajo de investigación se abordó en tres puntos para efectos de abordar el desarrollo de las cláusulas contractuales y su fuerza vinculante en la contratación estatal en Colombia, por ello, como elemento de inició se desarrollaron los antecedentes históricos de la contratación estatal en Colombia, desde los aspectos más importantes presentados con anterioridad a la expedición del Estatuto de la Contratación Pública, como también el desarrollo que se ha generado a la fecha respecto de los procesos de selección como las cláusulas propias de la administración. Seguidamente, se presentó el desarrollo jurisprudencial de las cláusulas contractuales y su fuerza vinculante en la contratación estatal en relación con los diferentes fallos emitidos por el Consejo de Estado, para terminar con los antecedentes del arbitraje en la contratación estatal en Colombia, dada la importancia y especial tratamiento que se le otorga a los mecanismos alternativos de solución de conflictos en las diferencias contractuales con el Estado.

\section{PALABRAS CLAVE}

Contratación Pública; Arbitramento; Cláusulas Compromisorias; Fuerza Vinculante.

\section{ABSTRACT}

This research work was addressed in three points for the purpose of dealing with the development of contractual clauses and their binding force in the state contracting in Colombia. As a starting point, the historical background of state contracting in Colombia was developed, from the most important aspects presented prior to the issuance of the Public Contracting Statute, as well as the development that has been generated to date with respect to the selection processes such as the administration's own clauses. Then, the jurisprudential development of contractual clauses and their binding force in state contracting was presented in relation to the different rulings issued by the Council of State, to end with the history of arbitration in the state contracting in Colombia, given the importance and special treatment to alternative dispute resolution mechanisms in contractual disputes with the State.

\section{KEYWORDS}

Public Procurement; Arbitration; Arbitration Clauses; Binding Force.

*Artículo de investigación 


\section{INTRODUCCIÓN}

La regulación de la contratación pública en Colombia ha sido muy amplia en todos sus momentos, su desarrollo ha estado ligado a muchos cambios e intereses, en algunos momentos se expidieron algunas normas que solo fueron vigentes por un tiempo no superior a un año, como otras normas que si llevan varios años pero que han sido modificadas de muchas formas, entre eso, los procesos de selección, forma de aplicación y contratación, entre muchos elementos propios de los fines del Estado que están relacionados con el cumplimiento de la satisfacción de los intereses de la administración como de la población.

Lo anterior va de la mano con el desarrollo jurisprudencial de las cláusulas contractuales y su fuerza vinculante en la contratación estatal de los diferentes fallos emitidos por el Consejo de Estado, donde se evidencia la incidencia de los acuerdos de las partes en cada contrato, el cual genera una situación especial respecto de la eficacia de las cláusulas respecto del marco normativo y su articulación en razón del ejercicio del principio de la autonomía de la voluntad y su respectiva exigibilidad por las partes.

Por último, el arbitraje en la contratación estatal en Colombia tiene gran importancia y especial tratamiento, pues en principio este método de solución hace parte del grupo de los mecanismos alternativos de solución de conflictos propiamente dicho del ámbito privado, pero que se extendió a los asuntos públicos para lograr obtener una resolución rápida y ajustada a derecho, sin que se debería desplegar de forma igual a las instancias judiciales de la jurisdicción contenciosa, lo cual ha permitido grandes resultados.

\section{ANTECEDENTES HISTÓRICOS DE LA CONTRATACIÓN ESTATAL EN COLOMBIA}

El desarrollo normativo de la contratación pública en Colombia, tiene sus inicios en la búsqueda establecer principios que garantizaran la transparencia y eficacia de los procesos, siendo necesario remitirnos al código Fiscal Nacional de 1912 en el que se dispuso a la licitación pública como de carácter obligatorio que posteriormente el Decreto extraordinario 2880 de 1959, estructuró las reglas para ejecutar ese tipo de licitaciones (López y Roa, 2015).
La expedición de diversas leyes que regularon algunos contratos de la administración pública como el "Estatuto Nacional de Compras" Decreto 351 de 1955, "Estatuto de Empréstito o de Operaciones De Crédito" Decreto 1050 de 1955, el "Estatuto de los Contratos Interadministrativos" Decreto legislativo de 1960, el "Estatuto Sobre Obras Publicas" Ley 4 de 1964, modificada por la Ley 36 de 1966 y el Decreto reglamentario 518 de 1965, pero, fue hasta el Decreto 150 de 1976, que se estableció una regulación unificada aplicable a los contratos que celebrará la Nación y los establecimientos públicos.

Posteriormente, se expidió el Decreto 222 de 1983, por medio de la cual se consignaron normas sobre contratos de la Nación y sus entidades descentralizadas, con una amplia normatividad con cláusulas exorbitantes como la terminación, modificación e interpretación unilateral; procedimientos como la licitación pública y la licitación privada; el registro de proponentes, y la tipificación de los contratos como el de obra pública, consultoría, suministro, compraventa y servicios (Ocaña, 2014, p.17).

Finalmente, con la Ley 80 de 1993 se dotó a las entidades públicas con la estructura y los principios de contratación, en la cual, se fijaron condiciones en las que se regirían las entidades estatales y particulares para la celebración de contratos, como los tipos de contratos, modalidades de selección, principios de la contratación, estableciendo la autonomía de la voluntad de las partes en la celebración de contratos (L. 80/1993, Art. 32).

El Estatuto de Contratación generó la obligatoriedad de aplicación a todo el Estado, de ello que:

Las entidades estatales están obligadas a cumplir el Estatuto General de Contratación Pública están autorizadas, no obstante, para acordar los asuntos de cada contrato dentro de una inmensa gama de posibilidades derivadas del derecho común, en el cual, a su vez, ante la ausencia de norma positiva expresa, remite a las costumbres y a la autonomía de la voluntad concertada entre las partes (PachónLucas, 2014, p. 3).

Además, la contratación del Estado contempló diferentes situaciones, desde la relación entre contratantes, como las obligaciones y la tipología del contrato, con el fin de satisfacer los fines del Estado, pero en general, la contratación tiene lugar 
cuando las entidades públicas contratan con personas de cualquier orden, dado que la satisfacción de la necesidad es un asunto que está inmerso en todos los eventos de la actuación, aunado que existe el deber constitucional para con las personas y sociedad el garantizar y desarrollar los derechos personalísimos como sociales.

En ese orden de ideas, la contratación constituye un mandado de obligatorio cumplimiento en las entidades, si no se ejecutan las acciones, programas, proyectos $\mathrm{y}$, cualquier decisión por medio de la consecución contractual, además que se generan sanciones del tipo penal, disciplinario y fiscal por el ordenador del gasto, también se afecta la esencia constitucional y legal para la cual se creó, alterando todo el ordenamiento jurídico y con ello consecuencias del orden judicial y presupuestal.

En la consecución contractual, se presentan diferentes tipos de contratos a saber, que se pueden clasificar así:

- Contrato de Obra Pública: Corresponde al contrato que se celebra para la construcción, mantenimiento, rehabilitación, instalación y en general para la realización de cualquier otro trabajo material sobre bienes inmuebles (Ley 80 de 1993, Art. 32), para este tipo de contrato por lo general se da un anticipo y la restante forma de pago se da versus ejecución (López y Roa, 2015, p. 24).

- Contrato de Consultoría: Es el que celebra la administración para la ejecución de proyectos de inversión, estudios de diagnóstico, prefactibilidad o factibilidad para programas o proyectos específicos, asesorías técnicas de coordinación, control e inspección, gerencia de obra o de proyectos, dirección, programación y la ejecución de diseños, planos, anteproyectos y proyectos (CE, s3, rad. 30802/2006, C.P. A. Hernández ).

- Contrato de Prestación de Servicios: Son los celebrados para desarrollar actividades relacionadas con la administración y se celebran para el cumplimiento de los deberes de la entidad pública.

- Contrato de Concesión: Se celebran con el fin de otorgar a una persona llamada concesionario la prestación, operación, explotación, organización o gestión, total o parcial, de un servicio público, como también la construcción, explotación o conservación total o parcial, de una obra o bien destinados al servicio o uso público $\mathrm{y}$, todas las actividades necesarias para la adecuada prestación o funcionamiento de la actividad objeto de concesión (L. 80/1993. Art. 32).

- Contrato de Compraventa: Corresponde al contrato en el que una de las partes se obliga a dar una cosa y la otra a generar una contraprestación por ese bien objeto del contrato, por lo general, las entidades adquieren bienes.

- Contrato de Suministro: Genera la obligación a realizar prestaciones periódicas o continuas en favor de la entidad pública, por ejemplo, la entrega de combustible, artículos de papelería, artículos de aseo y otros bienes y servicios técnicos.

Por regla general los contratos estatales están ligados a la prestación de servicios públicos, a la satisfacción de las necesidades que presenta la población y que están a cargo del estado, como también a solventar las necesidades que genera el funcionamiento del aparato estatal, lo que conlleva la generación de diversos tipos de contratos, y acuerdo a su objeto y cuantía se debe seleccionar el tipo de contrato y la modalidad de contratación.

\subsection{Procesos de selección en la contratación pública}

Es importante mencionar que diferentes formas de contratación, de tal manera que, la regulación ha establecido cinco diferentes modalidades de selección del contratista, dependiendo de las condiciones del objeto a contratar, la cuantía de la contratación, la naturaleza del contratante, entre muchos más factores.

En primer punto, se encuentra la modalidad de selección de Licitación pública (es la regla general: es decir que en principio todo proceso de selección de contratista deber realizarse a través licitación pública, a pesar que existen causales para realizarse a través de otros procedimientos), proceso utilizado por las entidades estatales para la elección del contratista a través de una invitación de carácter 
público que se dirige a todas las personas potencialmente interesadas en ejecutar un contrato, para que en igualdad de condiciones y bajo criterios objetivos, presenten ofertas entre las que se escogerá la oferta más favorable, además, la modalidad constituye la regla general de selección de contratista, definida en el numeral 1 articulo 2 ley 1150 de 2007. Se da publicidad al proceso a través de la página del Sistema Electrónico de Contratación Pública (SECOP), a la fecha fue creada una nueva plataforma denominada SECOP II.

Adicionalmente, existe el Concurso de méritos, modalidad prevista para la selección de consultores o proyectos, en los que se utilizará sistemas de concurso abierto o de pre calificación, en la modalidad de selección se premia el talento y la experiencia en la contratación, definida en el numeral 3 articulo 2 ley 1150 de 2007.

Por otra parte, existe la modalidad de Selección Abreviada que corresponde a la modalidad prevista en aquellos casos en que, por las características del objeto a contratar, la cuantía o destinación del bien, y que puedan adelantarse procesos simplificados con el fin de garantizar la eficacia de la gestión contractual y administrativa de la entidad pública. Se encuentra definida en el numeral 2 articulo 2 ley 1150 de 2007.

En este sentido, también encontramos la Contratación Directa la cual constituye ser excepcional pues su aplicación es de carácter restrictivo, es decir, contratar por esta modalidad permite la desviación de la transparencia y selección objetiva del contratista, a su vez, presenta causales claras y definidas para la utilización de la presente modalidad, definida en el numeral 4 articulo 2 ley 1150 de 2007.

Como última modalidad, se presenta la selección de Mínima Cuantía, siendo este un procedimiento sencillo y rápido para escoger al contratista en la adquisición de bienes, obras y servicios, cuyo valor no exceda el diez por ciento $(10 \%)$ de la menor cuantía de las Entidades Estatales, situación que conlleva que tenga menos formalidades que las demás y con características especiales. Es importante establecer que la selección de mínima cuantía se aplicará a todos los objetos de contratación cuando el presupuesto del contrato sea inferior o igual a la mínima cuantía de la Entidad Estatal, sin importar la naturaleza del contrato (Colombia Compra Eficiente, s.f.). Esta modalidad de selección fue definida en el artículo 94 de la ley 1474 de 2011, posteriormente reglamentada en los decretos 734 de 2012, 1510 de 2013, y 1082 de 2015.

Por último, el contrato es el elemento más importante que tiene el Estado para materializar y cumplir sus fines públicos, en razón de ello es que existen varios tipos de contratos junto a las diferentes etapas que deben cumplir en la consecución del vínculo contractual, siendo dos momentos importantes en el desarrollo contractual de la entidad, por un lado la elección idónea del tipo de contrato para luego desarrollar el procedimiento adecuado en aras de suplir la necesidad al interior de la entidad pública, el cual, tiene por característica la rigurosidad y exigencia en todas sus etapas, de tal manera que su inobservancia puede generar vicios en la relación contractual como las sanciones según el caso.

\subsection{Las cláusulas propias de la contratación estatal}

El Estatuto de contracción pública como marco de acción de las actuaciones del Estado, respecto a la ejecución contractual estableció:

Artículo 32. De los Contratos Estatales. Son contratos estatales todos los actos jurídicos generadores de obligaciones que celebren las entidades a que se refiere el presente estatuto, previstos en el derecho privado o en disposiciones especiales, o derivados del ejercicio de la autonomía de la voluntad, así como los que, a título enunciativo, se definen a continuación (L. 80/1993, Art. 32).

En consideración a lo anterior, el Consejo de Estado en sentencia de fecha agosto 20 de 1998 reiteró que el contrato estatal está regido por el principio de la autonomía de la voluntad junto a la protección del interés público y la vigilancia de los recursos (CE, s3, Auto14202/1998, C.P. J. Montes).

En el ámbito de la administración la rigurosidad de los procedimientos es una situación clara, especialmente en los asuntos contractuales, por ello las diferentes regulaciones que se han establecido en todas las acciones que deben suscitarse dentro de la etapa previa, ejecución y terminación contractual, pero es de resaltar que si bien la administración tiene ese marco de acción, también es cierto que puede enfocar sus decisiones en el 
marco de la autonomía, entre ello se encuentra la inclusión de cláusulas propias a los intereses del Estado.

Lo anterior en razón que el contrato es la manifestación de la autonomía de la voluntad de los interesados, pues se crean obligaciones de forma explícita o implícita, según el caso, conforme a lo indicado del mismo acuerdo o se desprenda por interpretación de su clausulado, pero también por el comportamiento de las partes en la ejecución del objeto contractual.

En el desarrollo contractual de la administración, se han establecido diferentes cláusulas que son propias del ámbito público, como ocurre con la:

- $\quad$ La caducidad

- La interpretación, modificación y terminación unilateral del contrato

- La reversión

- Las multas

- La declaratoria de incumplimiento y,

- La cláusula penal pecuniaria

Las anteriores cláusulas son algunas de las que se encuentran en la consecución de los contratos públicos, que están inmersas por la naturaleza de la entidad, con el fin de brindar garantías a la administración en obtener el mejor provecho del objeto, como también proteger de incumplimientos y tenga la potestad de sancionar al contratista de forma directa.

Así, las cláusulas exorbitantes son una facultad discrecional que tiene la entidad pública y que le han sido otorgadas para conjurar o remediar situaciones donde haya peligro o grave afectación del interés del Estado y salvaguardarlo sobre el interés particular (García y Mojica, sf).

Ahora, es de resaltar que la inclusión de las cláusulas excepcionales al derecho común, en las disposiciones contenidas en la Ley 80 de 1993, es una imposición del legislador para proteger a la Administración Pública, que genera una posición jurídica especial del Estado frente al contratante en el negocio jurídico público, en razón que este último prácticamente en nada interviene en la discusión y construcción de las cláusulas que son impuestas por la administración (Betancur, Londoño, y Múnera, 2017), pues la potestead se encuentra en manos de la administración y la aplicación del principio de la autonomía de la voluntad se genera en elementos que no modifiquen los presupuestos legales y jurisprudenciales establecidos en favor de la administración.

Lo anterior no es absoluto, pues si bien la interpretación del contrato se establece en el contrato como cláusula excepcional a favor de la administración, sin embargo, excepcionalmente y a favor de los contratistas puede aplicarse, como sucede, con la posibilidad que se lo otorga al contratista de terminar unilateralmente el contrato por modificaciones en más del $20 \%$ del valor del contrato (Pardo y Hernández, 2013), situación que se incorpora en terminos de equidad y protección de los derechos del particular, pues las clausuas si bien están en cabeza de la adminsitración, estas no pueden alterar la esencia de los presupuestos constitucionales del contratista.

En ese ejercicio de las cláusulas dentro del contrato, es importante mencionar que bajo el principio de la autonomía de la voluntad, también se generan acuerdos para efectos de solucionar las diferencias que se susciten del contrato, como es la de acudir a los mecanismos alternativos de solución de conflictos, presupuesto que se viene utilizando en muchos contratos, donde se prefiere acudir a tribunales de arbitramento que ejercer el mecanismo de controversias contractuales, dado que su resultado es muy demorado para los intereses de las partes, especialmente a la administración, que no puede dejar de cumplir sus deberes legales mientras se decide por una controversia dentro del contrato suscrito.

Por lo anterior, la autonomía que la Ley le otorgo a las entidades públicas para incorporar acuerdos tendientes a dinamizar sus procesos es sin duda alguna una situación trascendental para que los intereses prevalezcan en el ejercicio contractual, es más, la potestad de dirimir diferencias de forma directa con la parte es el punto de inicio para evitar congestionar más la justicia como evitar una demora innecesaria sin que se logre la satisfacción del objeto contractual, seguido del acceso de los medios alternos que la misma Ley permite al Estado acordar para la resolución de las controversias con la otra parte.

2.DESARROLLO JURISPRUDENCIAL DE LAS CLÁUSULAS CONTRACTUALES Y SU 


\section{FUERZA VINCULANTE EN LA CONTRATACIÓN ESTATAL}

El inicio del desarrollo jurisprudencial del Consejo de Estado respecto del pilar del acuerdo de voluntades, se genera con la providencia con radicado 25000-23-26-000-1993-8674-01(14112) del Consejero Ponente Ricardo Hoyos, en el caso de estudio donde en ejecución del contrato con la Empresa de Servicios Públicos EDIS, el contratista al finalizar entregó todos los elementos, presentó la cuenta de cobro por valor \$ 5'925.651 M/CTE., que correspondía a un saldo pendiente del contrato inicial y al valor de la adición ordenada, pero luego de numerosas comunicaciones enviadas a la entidad para el respectivo pago, la misma no canceló a pesar de haber recibido a satisfacción los trabajos ejecutados por el contratista, incumplimiento las cláusulas estipuladas en dicho contrato y de su respectiva adición.

La corporación consideró que cuando la administración pública incumple sus obligaciones, es responsable de los perjuicios que cause al contratista que si cumplió con las suyas, con fundamento en el art. 50 de la Ley 80 de 1993 según el cual "las entidades responderán por las actuaciones, abstenciones, hechos y omisiones antijurídicos que les sean imputables y que causen perjuicios a sus contratistas", eventos en los que "deberán indemnizar la disminución patrimonial que se ocasione, la prolongación de la misma y la ganancia, beneficio o provecho dejados de percibir por el contratista (CE, s3, rad. 25000-23-26-0001993-8674-01(14112)/2002, C.P. R. Hoyos).

En materia de responsabilidad contractual de la administración pública, el contratista tiene derecho a que la administración le indemnice la totalidad de los daños derivados del incumplimiento contractual, tanto los que se manifiestan como una disminución patrimonial (daño emergente), como los que se traducen en la privación de las utilidades o ganancias que esperaba percibir por la imposibilidad de ejecutar total o parcialmente el proyecto (lucro cesante) (CE, s3, rad. 25000-23-26000-1993-8674-01(14112)/2002, C.P. R. Hoyos).

En razón que los perjuicios causados a un contratista con el incumplimiento de la administración en el pago del valor del contrato, se indemnizan con la actualización del capital debido a título de daño emergente y con el reconocimiento de intereses desde el momento en que nació la obligación de pago hasta que éste se satisfaga (lucro cesante) (CE, s3, rad. 25000-23-26-0001993-8674-01(14112)/2002, C.P. R. Hoyos).

Desde la entrada en vigencia de la Ley 80 de 1993, en la contratación estatal la tasa del interés de mora aplicable, a falta de estipulación por las partes de una tasa de interés diferente, es la que establece el ord. $8^{\circ}$ del art. 4 , a fin de ofrecerle al contratista una indemnización por el daño sufrido y restablecer la equivalencia económica del contrato; de ahí que si la administración incumple con la obligación principal del contrato, debe reconocer los perjuicios moratorios que causó con su incumplimiento, esto es, los intereses moratorios, a la tasa que pactaron las partes o a falta de pacto, la que la ley suple, los cuales se presumen (CE, S3, rad. 25000-23-26-000-1993-867401(14112)/2002, C.P. R. Hoyos).

Ahora, en decisión de la Sala de Consulta y Servicio Civil, respecto del interés remuneratorio la Corporación estimó que límite a las tasas si la Junta del Banco de la República no las fija, se debe entender que a falta de norma mercantil que regule el monto máximo de los intereses remuneratorios se aplicará lo establecido en la Ley, pues en el marco del contrato celebrado, el principio del Pacta Sunt Servanda, conlleva que el mismo debe cumplirse en los términos en que fue pactado, por lo que solo será aplicable las leyes que limiten los montos de los intereses para la época en que se celebre el contrato (CE, SCC, Rad. 1276/2000, C.P. C. Hoyos, 2000). En razón al pacto contractual, se debe respetar las condiciones en las que se suscribió, entre ellas las normas de la época, así, el respeto por el margen de intereses que no genere la concurrencia de un delito como es la usura.

Posteriormente, en el proceso radicado número 70001-23-31-000-1996-05631-01 con ponencia del Magistrado Ramiro Saavedra, donde se demandó la declaratoria del rompimiento del equilibrio financiero del contrato $\mathrm{N}^{\circ} 588$ de 1985 , en razón a la aplicación de nuevas disposiciones jurídicas, por el impuesto que no estaba vigente a la fecha en que se celebró el contrato, pero INVIAS retuvo el 5\% de cada una de las cuentas de cobro que formuló desde mayo de 1995, con lo cual se produjo el rompimiento de la ecuación financiera del contrato en perjuicio suyo.

Por otra parte, en el desarrollo de la Licitación Pública Nacional No. D-03-96, la empresa de acueducto y alcantarillado de Bogotá ESP y SADEICO S.A., celebraron el Contrato SF-01- 
7000-0106-96, con el fin de construir el alcantarillado sanitario y pluvial a determinadas zonas residenciales, por valor de \$ 1.474.693.777 millones, bajo la modalidad de precios unitarios reajustables con un anticipo del $30 \%$ y una duración de 8 meses a partir del acta de iniciación de obras, el cual sufrió dos modificaciones (números 2 y 3), en las que se amplió el plazo de ejecución hasta el 18 de febrero de 1998.

La discusión jurídica del asunto se generó porque en ejecución del contrato se presentaron varias situaciones que causaron retrasos en la obra, provocando un desequilibrio económico y graves perjuicios, por lo que se rescindió el contrato, siendo demandadas las resoluciones por virtud de las cuales se rescindió el contrato de obra e impusieron multas, así como las que adoptan la liquidación sin reconocer los reclamos del contratista, argumentando el contratista que son ilegales, pues el ordenamiento jurídico no faculta para tomar dichas decisiones a una de las partes, ni menos aún en forma extemporánea y con desconocimiento del derecho de defensa.

Consideró el Consejo de Estado que los contratos válidamente celebrados son ley para las partes y sólo pueden ser invalidados por consentimiento mutuo de quienes los celebran o por causas legales, de tal manera que el principio "Lex Contractus, Pacta Sunt Servanda", que supone el carácter obligatorio para las partes y con efectos frente a terceros de un contrato celebrado, como resultado de

la autonomía de la voluntad de las partes, ahora, el contrato bien puede modificarse o extinguirse si éstas así lo convienen, así, una de la formas en que las partes pueden alterar los efectos finales del contrato válidamente celebrado y prever un efecto extintivo de las obligaciones que emanen del mismo, es a través de una condición expresa cuya ocurrencia destruye el vínculo derivado del negocio jurídico; generando que las partes son libres para subordinar la eficacia del contrato a un hecho o suceso futuro $\mathrm{e}$ incierto, negativo $\mathrm{o}$ positivo, cuya verificación resuelva el contrato y extinga las obligaciones pendientes, pero que fue establecida entre las partes (CE, s3, rad. 25000-2326-000-2001-00072-01(31838)/2007, C.P. R. Correa).

También podría modificarse estas situaciones si se incumpliera en forma "grave" el contrato por el contratista, conforme a lo pactado, se genera una condición resolutoria expresa, donde la entidad en libertad de resolver el contrato o insistir en su cumplimiento con el correspondiente pago de liquidación de daños y perjuicios acordada, opción que se genera siempre que a su vez hubiera satisfecho o cumplido sus prestaciones contractuales, porque cuando hubiera dejado de cumplir con lo pactado, en la forma y tiempo debidos, la inejecución o el retardo de la contratista en el cumplimiento de sus obligaciones determinada por la insatisfacción de la entidad, situación que impedía tomar esas decisiones unilaterales, so pena de infringir el propio contrato (CE, s3, rad. 25000-23-26-000-2001-0007201(31838)/2007, C.P. R. Correa).

El consejo de Estado, en el proceso con radicado 25000-23-26-000-2006-02062-01(34460) del año 2009, analizó el caso de las sociedades INGETEC S.A. ING., INGENIERIA S.A. e INFOGROUP LTDA., integrantes del Consorcio Intersidri, las cuales, demandaron a la Nación - Ministerio de Agricultura - Fondo de Cofinanciación para la inversión Rural -DRI - y la Secretaría Ejecutiva del Convenio Andrés Bello -SECAB- con la finalidad de obtener, de manera principal, la declaratoria de incumplimiento del Contrato No.001 de 2002, indemnización de los perjuicios $\mathrm{y}$, de manera subsidiaria, la declaratoria de rompimiento del equilibrio económico y la consecuencial condena al restablecimiento de la ecuación contractual (CE, s3, 25000-23-26-000-2006-0206201(34460)/2009, C.P. M. Guerrero).

La Corporación consideró que el Convenio Matriz de Cooperación y el Contrato celebrado con el Consorcio Intersidri, fueron ejecutados con dineros del Estado colombiano, siendo inaplicable

la inmunidad de jurisdicción, pues, con la celebración del negocio jurídico con un contratante amparado con dicha inmunidad sitúa a su cocontratante en un plano de desigualdad relativo, porque puede verse comprometida la eficacia del principio Pacta Sunt Servanda, en el entendido que un contrato válidamente celebrado obliga a las partes intervinientes a cumplirlo y, en este evento, una de las partes no podría ser conminada a cumplirlo, afectándose eventualmente la conmutatividad que, por regla general, informa los contratos (CE, s3, 25000-23-26-000-2006-0206201(34460)/2009, C.P. M. Guerrero). 
Esa desigualdad es de mayor proporción cuando la relación negocial se ejecuta en su totalidad con dineros del Estado colombiano y se impidiera a la parte ejercer el poder jurisdiccional sobre la controversia que se suscita en torno al contrato, por ello, en razón a la relación funcional y el contenido obligacional del negocio, el organismo internacional debe someterse al derecho interno y a la jurisdicción interna (CE, s3, Rad. 25000-23-26000-2006-02062-01(34460)/2009, C.P. M. Guerrero).

En razón a lo anterior, el principio Pacta Sunt Servanda no solo se limita a lo acordado en el contrato, pues la finalidad del mismo va más allá, dado que requiere a que las partes estén en un panorama de igualdad, en el marco de lo pactado, pues de presentarse alguna alteración beneficiosa a una parte se pierde la esencia del principio.

En otra providencia, se analizó la controversia producto del contrato de obra que celebró la Empresa de Energía de Bogotá con la sociedad DOMUS LTDA, presentando retrasos durante la ejecución de las obras, lo que condujo a la imposición de multas al contratista, aunado que se venció el término del contrato y las obras no fueron entregadas en su totalidad, por lo que la entidad declaró la caducidad del contrato, decisión que fue objeto de recurso en sede administrativa, donde se modificó y se declaró el incumplimiento del contrato, pero posteriormente, la E.E.B. liquidó en forma unilateral el contrato. El contratista demandó por presunto rompimiento del equilibrio económico, por una serie de circunstancias imprevisibles, que no le eran imputables y que afectaron la ecuación contractual.

El Consejo de Estado, precisó el alcance del acuerdo de voluntades en la determinación del rompimiento del equilibrio económico del contrato, considerando que el principio a tutelar del contrato generador de obligaciones es el Pacta Sunt Servanda, donde las estipulaciones acordadas deben prevalecer durante la ejecución del mismo y sólo pueden variarse por un nuevo acuerdo de voluntades, por ello, una de las partes no puede desconocer de forma unilateral las condiciones en las que se obligó, por lo contrario, se deben cumplir las prestaciones a su cargo exactamente en los términos en que se comprometió a hacerlo.

En razón a esto, las posibles variaciones que pueden surgir en las condiciones que dieron lugar a la celebración del respectivo contrato y que pueden afectar gravemente su cumplimiento, es bajo el principio del pacta sunt servanda, que ha sido moderado por la cláusula "Rebus Sic Stantibus, que corresponde a la regla jurídica contractus qui habent tractum succesivum vel dependiant de futuro rebus sic stantibus intelliguntur", donde, el acuerdo de voluntad de tracto sucesivo obliga a las partes contratantes en el futuro sólo si las condiciones originalmente previstas se mantienen sin alteraciones (CE, s3, rad. 25000-23-26-0001993-08365-01(14461)/2011, C.P. D. Rojas).

De tal manera, que la sujeción del pacto entre las partes tiene un alcance total siempre que se generen las mismas condiciones establecidas en el acuerdo de voluntades, puesto que de presentarse una alteración a esas situaciones nace la figura de la ecuación contractual, para poner en equilibrio los derechos y obligaciones de las partes.

Adicionalmente, en el proceso con radicado 2500023-26-000-1998-01826-01(24898), con ponencia de la Magistrada Stella Conto Díaz del Castillo, se resolvió el caso del alcance y efecto vinculante de la cláusula séptima convenida entre el Fondo Nacional de Vías (INVIAS) y el contratista Mario Alberto Huertas Cotes para efectos de actualización del contrato y que el demandante discrepó de esta por el mantenimiento del equilibrio económico del contrato.

La sala consideró que resulta improcedente la pretensión que solicita el reconocimiento del reajuste en los precios de acuerdo al índice de precios al consumidor DANE, ya que este no fue pactado, de acuerdo a ello planteo lo siguiente: Partiendo "de la base de que los efectos finales del negocio jurídico son el resultado no solo de lo estipulado por las partes, sino igualmente de lo ordenado por la ley, dentro de lo que conoce la doctrina como el fenómeno de la "integración del contrato", es pertinente señalar que frente al índice para actualizar o indexar cuentas en materia contractual, en vigencia del Decreto Ley 222 de 1983, normatividad que, como se explicó, rige el presente contrato, no existía ningún imperativo que impusiera la utilización del Índice de Precios al Consumidor certificado por el DANE, sin que ello comporte que la Sala desconozca su común utilización. De manera que se trataba de un aspecto sujeto a la autonomía contractual, es decir, las partes resolvieron la fórmula que utilizarían para mantener el precio, sin perjuicio de la inflación. Al punto que una vez convenido, el juez no puede, 
salvo vicios palmarios de vulneración de dicha autonomía, alterarlo (CE, s3, rad. 25000-23-26000-1998-01826-01(24898)/2012, C.P. S. Conto).

De otra parte, en la providencia del 29 de agosto de 2012, con ponencia del Magistrado Danilo Rojas Betancourth, el caso bajo análisis se concretó en el cumplimiento o no del contratista en el contrato No. 058 de diciembre de 1991, para lo que la Sala considera que el contratista no probó la ejecución total del contrato, esto es, acreditó con la entrega del informe final algunas prestaciones como el acopio o recolección de legislación colombiana en materia de archivos y documentación, en razón a la aplicación del principio "Lex Contractus, Pacta Sunt Servanda", de conformidad con el material probatorio aportado por las partes del cumplimiento de las obligaciones acordadas, el contratista no cumplió lo establecido en el contrato, pero tampoco se demostró el cumplimiento de la entidad contratante, por lo que la Corporación liquidó el contrato tomando el valor otorgado como anticipo el pago del servicio prestado, ya que no se logró demostrar la amortización de este. (CE, s3, rad. 05001-23-25-000-1994-01059-

01(21315)/2012, C.P. D. Rojas)

El Consejo de Estado en el proceso radicado 20001-23-31-000-2000-01310-01(24217) de ponencia del Magistrado Danilo Rojas Betancourth, analizó si el retraso en el pago parcial del anticipo, tiene la virtualidad de generar un incumplimiento de la entidad contratante y ser susceptible de ser indemnizado. Siendo del caso el alcance de lo pactado en relación con la forma de pago, donde los contratos sinalagmáticos tienen la característica de que no pueden ser exigibles para una parte, hasta tanto la otra no cumpla lo que le corresponde, así que, para poder solicitar ante el juez la declaratoria de incumplimiento, de una parte o de la totalidad del contrato por parte del contratista, es indispensable que éste, a su vez, acredite que cumplió todas y cada una de sus obligaciones contractuales, de manera tal que hace exigibles las de su co-contratante, conforme a la relación pactada.

Por lo tanto, no existió incumplimiento, habida cuenta que no se acreditó dentro del proceso que la parte demandante satisfizo a cabalidad sus obligaciones y que no se sustrajo a los compromisos pactados, como tampoco que la entidad haya incurrido en un incumplimiento de tal entidad, que se tradujese en frustrar la posibilidad de cumplimiento del negocio jurídico, dado el carácter conmutativo del mismo, que si bien se presentó un retraso en el pago de una parte menor del "anticipo", este incumplimiento no tiene la entidad suficiente como para alterar la normal ejecución del negocio jurídico, así, al no demostrarse por parte del contratista demandante un incumplimiento serio, grave, determinante de la Administración, que lo hubiese puesto en una razonable imposibilidad de cumplir, no podría alegar en su favor la excepción de contrato no cumplido (CE, s3, rad. 20001-23-31-000-200001310-01(24217)/2013, C.P. D. Rojas).

De las sentencias analizadas se puede inferir, que el Consejo de Estado en sus múltiples decisiones frente a las acciones contractuales, le da una gran relevancia al material probatorio aportado por las partes, a efectos de solicitar perjuicios o alegar el mentado desequilibrio económico del contrato, el cual, debe ser justificado, soportado y probado, puesto que

el incumplimiento contractual supone la inobservancia de las obligaciones contraídas por virtud de la celebración del acuerdo negocial, infracción que bien puede cristalizarse por cuenta del cumplimiento tardío o defectuoso de las condiciones convenidas o por el incumplimiento absoluto del objeto del contrato, no obstante, dicho incumplimiento no solo se presenta por la inobservancia de las estipulaciones contenidas en el texto contractual, sino en todos los documentos que lo integran (CE, s3, rad. 25000-23-26-0002011-01090-01 (50907)/2016, C.P. M. Velásquez).

\subsection{Incidencia de la cláusula compromisoria como medio para la solución de las controversias contractuales}

La cláusula compromisoria es la forma en la que las partes permiten y limitan su actuar para efectos de solucionar sus diferencias y obtener su fin esperado, con ello también se limita la competencia del Juez natural para solucionar este tipo de discusiones contractuales, en ese ejercicio se desprende todo tipo de reclamaciones y formas de solución.

Así, en el análisis de la procedencia del reconocimiento reclamado por el demandante por concepto de mayores costos superiores al precio contratado, por el pago tardío de las mayores cantidades de obra y obras extras, como consecuencia de la demora en la suscripción de los 
contratos adicionales. Se indicó por la Corporación que a pesar del acuerdo con el principio Pacta Sunt Servanda, el contrato es ley para las partes, en la ejecución del contrato se pueden presentar situaciones extraordinarias, posteriores a su celebración, imprevistas e imprevisibles, ajenas a las partes o imputables a una actuación legal de la contratante, que pueden alterar la ecuación financiera del mismo en forma anormal y grave, de tal forma, que sin imposibilitar su ejecución, lo hacen más oneroso para la parte afectada.

De modo que, se conoce como el rompimiento del equilibrio económico del contrato, caso en el cual, en virtud del principio Rebus Sic Stantibus, surge el deber de restablecerlo, bien sea mediante una indemnización integral de perjuicios, en el caso del hecho del príncipe, en el cual, la afectación de la ecuación contractual proviene de una medida de carácter general proferida por la misma persona de derecho y obligaciones del contratante particular, situación que se vio reflejada (CE, s3, rad. 2500023-26-000-1998-03066-01(20912)/2014, C.P. D. Rojas).

Así mismo, en el proceso con radicado 68001-2331-000-2002-02796-01 (41008), se decidió si durante la ejecución del contrato de obra pública No. 233 de 2000, se presentó un incremento desbordado del precio del asfalto sólido que le resultó imprevisible, pues el cálculo con base en el cual había estructurado su propuesta económica, correspondía al aumento que marcaba ese producto durante el año anterior a la apertura de la licitación, es decir, año 1999, el cual fue rebasado inesperadamente en el año 2000, época en que tuvo lugar la presentación de la propuesta y parte de la ejecución del contrato.

Consideró la Sala que acudir a los instrumentos de ajuste y revisión de precios, es la manifestación del principio de mantenimiento del equilibrio económico del contrato, propio de los contratos conmutativos y onerosos, a cuya categoría pertenecen gran parte de los contratos estatales, garantizando que se mantengan inalterables las contraprestaciones establecidas en el mismo, por ello, las partes no pueden renunciar, antes de que se presente el supuesto de ruptura, a que se restablezca el equilibrio económico (CE, s3, rad. 25000-23-26000-2011-01090-01 (50907)/2016, C.P. M. Velásquez).

Dado que no se puede renunciar a lo que desconoce, pues los contratantes no saben cuándo, cuántas veces y por qué período se producirá la variación de los precios, siendo inválido renunciar de los reajustes de precios a través de un acuerdo convencional. Esto implica que la cláusula de renuncia a los reajustes de precios se torne ineficaz al momento de solicitar la revisión de los precios del contrato. Bajo lo anterior, la Sala declaró la nulidad de la cláusula prevista en el numeral 5.19 del pliego de condiciones correspondiente a la licitación pública SCV-011-2000, por objeto ilícito. (CE, s3, rad. 68001-23-31-000-200202796-01 (41008)/2015, C.P. H. Andrade)

Igualmente, en decisión del 30 de julio de 2015 de la Magistrada Stella Conto Díaz del Castillo, la Sala resolvió el asunto por el presunto incumplimiento alegado por los contratantes, respecto de las obligaciones pactadas, donde se evidenció que en cumplimiento a lo que se obligaron las partes en el contrato y lo que en realidad cumplieron y lograron demostrar, el demandado

no probó el incumplimiento alegado, en tanto el consorcio presentó los informes dentro de los plazos convenidos. Y, en cuanto a los aspectos técnicos, la entidad no demostró el incumplimiento de los parámetros de los términos de referencia del proceso de selección o lo acordado en el contrato. En ningún momento la administración demandada reparó en las labores ejecutadas, tampoco realizó observaciones concretas o específicas a los informes, de lo que se debe concluir que el contratista cumplió con sus obligaciones y la entidad desconoció la obligación principal de pagar (CE, s3, rad. 25000-23-26-000-2001-0204402(33925)/2015, C.P. S. Conto), faltando a la contraprestación establecida en el contrato.

En la providencia con radicado 26-000-200201433-01(33790), se solicitó declarar el incumplimiento por parte de entidad contratante del contrato de obra No.017 de 1997 y el pago de los perjuicios causados por el desequilibrio contractual en razón del clima, las condiciones topográficas e hidroclimáticas, orden público y transporte que no fueron reconocidos, donde se consideró que el contrato es la expresión de la autonomía de la voluntad y se rige por el principio "Lex Contractus, Pacta Sunt Servanda", donde los contratos válidamente celebrados son ley para las partes y sólo pueden ser invalidados por consentimiento mutuo de quienes los celebran o 
por causas legales (CE, s3, rad. 25000-23-26-0001998-03066-01(20912)/2014, C.P. D. Rojas).

Adicionalmente, en el proceso con radicado 2500023-26-000-2011-01090-01(50907) de la sección tercera, se analizó el caso del contrato suscrito entre el Distrito Capital - Secretaría de Educación y el consorcio P\&P SAI Rivera, se ejecutó la obra con el sistema de precios globales, con un plazo de trescientos treinta (330) días calendario, pero que fue suspendido, adicionado, prorrogado y liquidado por mutuo acuerdo. No obstante, fue solicitada la declaración de incumplimiento del Contrato por causas imputables a la entidad contratante y el reconocimiento de los perjuicios derivados de la mayor permanencia en obra por las distintas adiciones y suspensiones, así como el pago de las mayores cantidades de obra ejecutada.

De lo que se desprende que el incumplimiento contractual supone la inobservancia de las obligaciones contraídas por virtud de la celebración del acuerdo negocial, infracción que bien puede cristalizarse por cuenta del cumplimiento tardío o defectuoso de las condiciones convenidas o por el incumplimiento absoluto del objeto contratado, empero, el incumplimiento no solo se presenta por la inobservancia de las estipulaciones contenidas en el texto contractual, sino en todos los documentos que lo integran, como los pliegos de condiciones o términos de referencia, que corresponde a la formación del vínculo jurídico (CE, s3, rad. 25000-23-26-000-2011-0109001(50907)/2016, C.P. M. Velásquez).

Ahora, una vez el contrato se liquida por mutuo acuerdo entre las partes, el documento en el que consta la misma contiene un consenso de los extremos contratantes que no puede ser desconocido posteriormente ante la instancia judicial por parte de quien lo suscribe, salvo que se invoque algún vicio del consentimiento o se deje expresa constancia de la existencia de salvedades o discrepancias respecto del cruce de cuentas que allí se consigna y pese, a que el actor en el acta de liquidación del negocio jurídico, consigno salvedades, la sala observó que no se pudo comprobar el incumplimiento por parte de la Entidad (CE, s3, rad. 25000-23-26-000-201101090-01(50907)/2016, C.P. M. Velásquez).

En este sentido, se evidencia que el Consejo de Estado ha mantenido y ratificado la prevalecían del principio Pacta Sunt Servanda, como la fuerza obligatoria del contrato mediante el principio del respeto a la palabra empeñada, en la medida en que las cláusulas del negocio jurídico resultan vinculantes para las partes y deben ser respetadas y cumplidas a lo largo de toda la ejecución del contrato (CE, s3, rad. 70001-23-31-000-199605631-01(15119)/2003, C.P. R. Saavedra).

En consecuencia, el Código Civil Colombiano en su artículo 1602 establece que "Todo contrato legalmente celebrado es ley para los contratantes, y no puede ser invalidado sino por su consentimiento mutuo o por causas legales", disposición que demuestra la importancia que reviste a la hora de ejecutar un contrato, la voluntad de las partes que se obligaron mediante su celebración (CE, s3, rad. 70001-23-31-000-1996-05631-01(15119)/2 2003, C.P. R. Saavedra).

En efecto el legislador en el artículo 40 de la ley 80 de 1993, reitera expresamente la aplicación de dicho principio, al indicar que "Las entidades podrán celebrar los contratos y acuerdos que permitan la autonomía de la voluntad y requieran el cumplimiento de los fines estatales".

Por consiguiente, la prevalencia del principio Pacta Sunt Servanda, no tiene un poder supremo (omnipotente), si bien es cierto, el contrato es ley para las partes, este no puede desconocer la normatividad vigente, es decir, que para el Consejo de Estado el acuerdo de voluntades no debe desconocer el ordenamiento jurídico vigente, para la fecha en se pactó el acuerdo de voluntades, y en caso que se expida norma posterior y que contrarié lo pactado, para efectos del alcance del contrato, se tendrá en cuenta la normatividad vigente para la fecha en que se suscribió el mismo.

En consecuencia, cuando se examina el incumplimiento de uno los extremos del negocio jurídico, del contenido obligacional de aquellas estipulaciones que de manera libre, voluntaria y vinculante acordaron las partes al tiempo de su celebración, faculta al contratante, para que, en sede judicial o arbitral, pueda solicitar la resolución del respectivo vínculo negocial o su cumplimiento, mediante la Cláusula Contractual o Compromisoria, en donde las partes tienen la libre disposición de determinar que sus controversias serán resueltas por los amigables componedores.

Por último, en ejercicio del acuerdo de voluntades de las partes y de la inclusión de cláusulas propias a los intereses de las partes, especialmente la compromisoria, de la cual se desprenden varias 
situaciones en el desarrollo contractual, donde las partes tienen una limitante en el comportamiento e interés para dirimir diferencias de su propia ejecución, es del caso cuando la administración y contratista deben ajustar en cantidad, tiempo y otros factores propios del objeto contractual, o en la ejecución se generan algunos valores adicionales, se puede presentar un acuerdo para afrontar estos y obtener una solución amigable, como también se pueden presentar otros medios para solucionar cualquier otro tipo de discrepancia, situación que tiene plena validez y procedencia, pues en el marco de la ley, el interés de las partes prevalece en razón de la forma del método de solución.

Además, en el caso que no se obtenga una solución directa y en sede administrativa, pero que se haya establecido la cláusula compromisoria para efectos de acudir a un tribunal de arbitramento, está deberá ser asumida por las partes, dado que acudir a otras instancias solo generará una falta de competencia de conocer del asunto en virtud de la cláusula pactada en el contrato, situación que brinda seguridad jurídica a las partes.

\section{ANTECEDENTES DEL ARBITRAJE EN LA CONTRATACIÓN ESTATAL EN COLOMBIA}

La Ley 1563 de 2012, por medio de la cual se expide el Estatuto de Arbitraje Nacional e Internacional, en su artículo $1^{\circ}$, definió que el arbitraje: "Es un mecanismo alternativo de solución de conflictos mediante el cual las partes difieren a árbitros la solución de una controversia relativa a asuntos de libre disposición o aquellos que la ley autorice" (L. 1563/2012), en la cual, se hace entrega a un tercero la potestad de resolver cualquier tipo de diferencia entre las partes, lo cual se realiza por medio de un compromiso previamente establecido al negocio jurídico o que puede acordarse en el punto de controversia.

Es así, que el arbitraje se deriva por un acuerdo privado, entonces se debe iniciar de la premisa que tiene origen en la voluntad de las partes del conflicto (Guasp, 1956), además, de tener un carácter dualista, es decir, entre el arbitraje nacional e internacional que si bien el arbitraje es un medio alternativo de resolución de conflictos, este se aplica en materia civil, comercial y laboral, a diferencia de la aplicabilidad que se da en materia administrativa, debido a que ha sido reducido, pues en ella, está presente la noción del interés público, el cual, prevalece sobre los intereses individuales de los administrados (Rodriguez, 2012).

Las partes se obligan no sólo a lo que en ellos se expresa, sino a todas las cosas que emanan precisamente de la naturaleza de la obligación o que por ley le pertenecen a ella sin cláusula especial. En los contratos bilaterales y conmutativos, teniendo en cuenta la correlación de las obligaciones surgidas del contrato y la simetría o equilibrio de prestaciones e intereses que debe guardar y preservarse, la parte que pretende exigir la responsabilidad del otro por una conducta alejada del contenido del título obligacional debe demostrar que, habiendo cumplido por su parte las obligaciones del contrato, su co-contratante no cumplió con las suyas, así, en el desarrollo procesal del proceso, las partes deben probar el cumplimiento de las obligaciones para efectos de las solicitudes del reconocimiento de los perjuicios causados por el desequilibrio contractual (CE, s3, rad. 25000-23-26-000-2002-0143301(33790)/2015, C.P. S. Conto).

Ahora, el arbitraje en el derecho administrativo tiene una incidencia muy particular, donde se evidencia que:

En el Derecho Administrativo la aplicación del arbitraje como medio o mecanismo de resolución de controversias resulta restringido, puesto que la actuación de la Administración Pública se corresponde con: el principio de legalidad (...); y, la satisfacción del interés público, lo que limita la posibilidad de disposición de la Administración Pública, pues gran parte de la actividad administrativa se realiza en ejercicio de potestades regladas, en las cuales el ordenamiento jurídico determina todas y cada una de las acciones que debe cumplir el órgano o ente administrativo para la correcta ejecución de la misma. (Chirinos, 2010, p. 237).

Por lo anterior, se han desarrollado mecanismos alternativos para la solución de conflictos, pero es del caso, que sobre contratación estatal han resultado novedosos e interesantes por la agilidad, economía y eficacia consecuentes con su aplicación, como son del caso el arbitramento y la conciliación judicial o prejudicial (ReyesSarmiento y Guzmán-Suárez, 2014), de manera general.

El arbitramento en la solución de las controversias contractuales generadas por un contrato encuentra 
una serie de contingencias, entre las cuales se encuentra la indispensable inversión de orden pecuniario para obtener la emisión de un laudo arbitral en forma ágil, siendo inaplicable el principio de gratuidad que se brinda en la justicia contenciosa administrativa, convirtiendo esta figura en un dispositivo negocial-procesal.

El consejo de Estado consideró que desde la teoría del contrato, configura obligaciones que tienen su fundamento en el principio de la autonomía de la voluntad, con carácter de ser correlativas, por una libre y autónoma decisión de acudir a este procedimiento de intercambio económico, donde la esencia del principio del Pacta Sunt Servanda, se tiene que el contrato tiene fuerza obligatoria y debe ser cumplida a lo largo de toda la ejecución del contrato, ahora, frente a los vacíos que las partes hayan podido dejar respecto de la regulación de la relación contractual, es decir, se presentan lagunas, en general, la ley debe operar sólo de manera supletiva, frente a los vacíos que las partes hayan podido dejar respecto de la regulación de su relación y sólo para llenar esas lagunas de la voluntad (CE, s3, rad. 70001-23-31-000-199605631-01(15119)/ 2003, C.P. R. Saavedra).

La justicia arbitral conlleva la posibilidad de sustituir la justicia ordinaria, puesto que al tratarse de un mecanismo que concreta el principio de la economía procesal y su celeridad en la emisión de decisiones mediante el laudo arbitral, siendo el arbitraje un mecanismo alterno de resolución de conflictos en materia de contratos estatales, que genera confianza, al igual que la justicia formal estatal y, "reconocimiento de procedimientos menos formales complementan las opciones a las cuales pueden acudir los contratantes para resolver sus disputas” (Romero, 2003, p. 123).

Respecto de la justicia arbitral ofrece ventajas que terminan por convertirla en una alternativa llamativa, por su efectividad y goza de las siguientes ventajas:

(...) En primer término, el factor tiempo, en este sentido, y frente a la larguísima duración de los procesos contencioso-administrativos, en el procedimiento arbitral, «si las partes no hubieran dispuesto otra cosa, los árbitros deberán dictar su laudo en el plazo de seis meses, contados desde la fecha en que hubieran aceptado la resolución de la controversia» (art. $30 \mathrm{LA}$ ). El no respeto de este plazo es una de las causas de nulidad del laudo arbitral (art. 45.3 LA). En segundo término, es importante resaltar el factor flexibilidad, por cuanto el procedimiento arbitral puede adaptarse a las circunstancias de cada caso, es un traje a la medida de cada una de las partes (art. 21.2 LA). De ese modo, y respetando algunos principios esenciales (audiencia, contradicción), la voluntad de las partes va a ser determinante para el desarrollo del procedimiento, en el que el principio anti formalista, siempre respetando ciertas reglas, juega un papel relevante. En tercer lugar, ha sido destacado el factor competencia y especialización puesto que corresponde al enjuiciamiento de la controversia a un conjunto de expertos, distintos en cada caso y conocedores de las materias objeto de debate. En cuarto lugar, ha sido puesto de relieve el tema económico, aunque, a nuestro parecer, este argumento resulta más que discutible aplicado al ámbito administrativo, pues frente a la gratuidad del recurso administrativo ordinario, el arbitraje comporta un coste. Por último, la introducción del arbitraje en el Derecho administrativo, así como otras figuras de corte convencional o negociar, inaugura un nuevo sistema de relaciones entre las Administraciones Públicas y los ciudadanos que la doctrina francesa denomina la «táctica de la seducción», en un intento de legitimación democrática de la actividad administrativa en detrimento de la actividad imperativa clásica. (Trayter, 1997, p. 76).

Por ello, la justicia arbitral ofrece ventajas, bajo el entendió que es una opción con fundamento constitucional, desarrollada por medio de la Ley 1563 de 2012, además de la oportunidad que se generó con la derogatoria del artículo 69 de la ley 80 del 1993, que prohibía la utilización de los mecanismos de solución directa en las controversias contractuales, siendo ahora procedente resolver los asuntos de esta naturaleza si las ventajas que ofrecen terminan siendo efectivas al momento de solucionar controversias contractuales.

De otra parte, la procedencia del arbitraje nace desde la consecución del compromiso o cláusula compromisoria que se deja inmersa en la celebración del contrato, la cual está ligada al cumplimiento de los requisitos del artículo 1502 del Código Civil: "El consentimiento de las partes exento de vicios, la capacidad de las partes, un objeto lícito, una causa lícita y solemnidad, fundamentos indispensables para la exigibilidad y eficacia de la cláusula". 
En esas consideraciones, la contratación estatal y en lo que corresponde al estatuto anticorrupción, permite la solución de conflictos a causa de la celebración, ejecución o liquidación del contrato estatal a través del mecanismo de arbitraje, siempre que se incluya la cláusula compromisoria en el contrato (Reyes-Sarmiento y Guzmán-Suárez, 2014), habida cuenta que su omisión limita la procedencia de este medio y obliga a las partes acudir a la justicia ordinaria.

La búsqueda del arbitraje permite a las partes la posibilidad de negociar en el marco de la voluntad del negocio jurídico, con el fin de resolver las controversias con base en el acuerdo, de tal manera que su campo de acción se enmarca en un acuerdo por acceder al tribunal de arbitramento, quienes con base en esa potestad que les confiera la ley y las partes toman una decisión con base a los criterios objetivos ya sea en equidad o en derecho.

En la administración pública la solución de controversias contractuales es un asunto de gran interés, tan solo es del caso mencionar, que la entidad contrató una obra para suplir una necesidad urgente a la población, pero dicha obra no se logró terminar y por el contrario generó diferencias con el contratista, esperar para solucionar ese asunto solo genera un daño y no soluciona la afectación, por ello, acudir al arbitramento beneficia no solo a la entidad pública, sino que también lo hace para toda la población.

La dinámica pública está inmersa en grandes exigencias y deberes, por eso los procesos y actuaciones deben efectuarse de forma ágil para materializar los derechos de las personas, sin importar los problemas o inconvenientes que se generen, dado que el deber del Estado es cumplir con los preceptos normativos como proteger a los administrados, de tal manera, que más allá de que el arbitraje sea un mecanismo alternativo de solución de conflictos, es una herramienta que está al alcance de la administración para optimizar sus actuaciones y obtener resultados eficaces con base a las necesidades reales de la administración.

En este sentido, es claro que la voluntad privada, tiene fuerza normativa, pues a través de ella, las partes del conflicto alcanzan una solución al mismo, mediante una transacción que tiene efectos de cosa juzgada. El caso específico de la conciliación como mecanismo alternativo al judicial, en donde, la naturaleza misma de la conciliación exige el ejercicio pleno de la autonomía de la voluntad y si se logra llegar a un acuerdo, éste tendrá la misma fuerza que una decisión judicial, lo cual vislumbra, una vez más, la fuerza jurídica que tiene la voluntad exenta de vicios para producir efectos jurídicos, siempre que respete el orden público y las buenas costumbres, en los términos señalados por la Constitución Política.

Ahora bien, la capacidad que tiene la autonomía de la voluntad para producir efectos jurídicos bajo las condiciones y alcances que los particulares definan es perfectamente posible en un contexto privado o comercial, en el que están en juego únicamente intereses particulares de carácter económico o personal, y que no tienen incidencia directa en el devenir de la sociedad, sólo acuerdo de voluntades de las partes o el reconocimiento libre y espontáneo que alguna de ellas manifieste en torno de las razones de hecho y de derecho que contra ella se presenten, si bien es necesario no resulta suficiente para que la conciliación sea aprobada en materia Contencioso Administrativa, puesto que el legislador exige que, al estar de por medio los intereses y el patrimonio público, el acuerdo conciliatorio debe estar soportado de tal forma que en el momento en el cual se aborde su estudio, al juez no le quepan dudas acerca de la procedencia, la legalidad y el beneficio -respecto del patrimonio público- del mencionado acuerdo conciliatorio.

\section{CONCLUSIONES}

El Estado en ejercicio de su normal funcionamiento ejercen diferentes procesos, que se desarrollan por medio de la celebración de contratos, siendo esta la principal herramienta de gestión pública, que a su vez es un negocio jurídico que tiene un interés económico, como ocurre para con el contratista, quien pretende obtener una remuneración y ganancia por su actividad ejecutada, pero las partes tienen un fin común, la consecución y satisfacción de la necesidad objeto del contrato, conforme a las condiciones establecidas en el contrato y demás que se generen en la ejecución de la misma.

En relación con el vínculo contractual se presentan muchas situaciones que pueden generar diferencias y futuras controversias contractuales, dado que en todo el proceso de ejecución o liquidación del contrato las condiciones pueden variar o situaciones que generan desacuerdos por temas de cumplimiento, recibo o terminación en caso de obras o suministros, como las de garantía por las actividades realizadas, lo cierto, es que 
indistintamente el objeto del contrato, por muchas circunstancias se pueden presentar inconvenientes que seguramente no se podrán resolver de forma directa en sede administrativa y trascenderá a otras esferas como la justicia ordinaria o mecanismos alternativos de solución de conflictos.

Dado el acuerdo que se genera en los contratos, es producto de la potestad de la administración y el contratista, tanto en la imposición de las cláusulas exorbitantes de la administración como el acuerdo sobre otros asuntos como ocurre con la cláusula compromisoria, por medio de la cual se genera el acceso y competencia a instancias jurisdiccionales como el tribunal de arbitramento como lograr el arreglo directo. Así, en la aplicación de los mecanismos alternativos, es de gran importancia el arbitraje, pues en muchos casos las entidades públicas establecen la cláusula para efectos de someter las sus diferencias, situación que es una clara materialización de la autonomía de la voluntad de las partes "Pacta Sunt Servanda" y principios que regulan las actuaciones públicas, por lo que acudir a este tipo de justicia es constitucionalmente necesaria y procedente, con el ánimo de lograr eficiencia y eficacia en las decisiones de la administración.

Por último, el arbitraje en la contratación estatal en Colombia tiene gran importancia, que se genera para lograr obtener una resolución rápida y eficaz, sin que se deba acudir a instancias de la jurisdicción contenciosa administrativa, dado que la justicia arbitral genera seguridad jurídica tanto para las partes como para el ordenamiento jurídico colombiano, pues las decisiones son en el marco de los presupuestos establecidos en el contrato como de las condiciones que se generan en la ejecución del mismo, siendo un grupo de diferentes factores que serán objeto de revisión en sede del Tribunal, todo en función de los principios constitucionales y legales del arbitramento como los intereses del Estado.

\section{REFERENCIAS BIBLIOGRÁFICAS}

I. Betancur, G. L., Londoño, C., y Múnera, M. (2017). Las cláusulas excepcionales en la contratación estatal. Revista Nuevo Derecho(13), 1-31.
II. Colombia Compra Eficiente. (sf.). Manual de la Modalidad de Selección de Mínima Cuantía. Recuperado el Noviembre de 2018, de https://www.colombiacompra.gov.co/site s/default/files/manuales/cce manual_min ima_cuantia_web_03 0.pdf

III. Chirinos, L. M. (2010). El Arbitraje como medio alterno de resolucion de conflictos en la Administracion Pública. Estudios de Derecho, 67(150), 229-252.

IV. García, L. J., y Mojica, J. A. (s.f.). Características de las cláusulas exorbitantes en el contrato estatal. Cúcuta: Universidad Libre. Obtenido de http://www.unilibrecucuta.edu.co/ojs/ind ex.php/hipotesis/article/download/135/12 $\underline{7}$

V. Guasp, J. (1956). El arbitraje en el derecho español. Bosch. Barcelona. .

VI. López, L. A., y Roa, C. C. (2015). Manual de contratación pública para contratos de obra de infraestructura vial (invias-idu$u m v$ ). Bogotá: Universidad Católica de Colombia.

VII. Ocaña, J. E. (2014). Análisis crítico de la ley de contratación.(tesis de pregrado). Universidad de Nariño, Pasto, Colombia. Recuperado de: http://biblioteca.udenar.edu.co:8085/aten ea/biblioteca/90558.pdf.

VIII. Pachón-Lucas, C. (2014). Contratación pública: Análisis normativo descripción de procedimientos. Bogotá, Colombia: Ecoe Ediciones.

IX. Pardo, N., y Hernández, C. (2013). La interpretación de las cláusulas del contrato estatal en el marco del orden jurídico. Criterio Jurídico Garantista, 5(8), 124135.

X. Reyes-Sarmiento, L. M., y GuzmánSuárez, S. P. (2014). Estado actual de los mecanismos para la solución de conflictos contractuales en el Estado colombiano. DIXI, 16(19), 19-35.

XI. Rodriguez, M. (2012). Aproximacion al Regimen del Arbitraje Nacional del 
Nuevo Estatudo del Arbitraje en Colombia, Ley 1563 de 2012. Revista de Derecho Privado, 23, 367.

XII. Romero, L. (2003). El Arbitraje en la contratación estatal. (tesis de pregrado). Pontificia Universidad Javeriana, Bogotá, Colombia. Recuperado de: https://www.javeriana.edu.co/biblos/tesis /derecho/dere5/TESIS48.pdf

XIII. Trayter, J. M. (1997). El Arbitraje de Derecho Administrativo. Dialnet, (143), 75-106. Recuperado de: https://dialnet.unirioja.es/servlet/articulo? $\underline{\text { codigo }=17354}$

\section{REFERENCIAS JURISPRUDENCIALES}

XIV. CE, s3, Auto14202/1998, C.P. J. Montes (Consejo de Estado 20 de Agosto de 1998).

XV. CE, SCC, rad. 1276/2000, C.P. C. Hoyos (Consejo de Estado 05 de Julio de 2000).

XVI. CE, s3, rad. 25000-23-26-000-19938674-01(14112)/2002, C.P. R. Hoyos (Consejo de Estado 21 de Febrero de 2002).

XVII. CE, s3, rad. 70001-23-31-000-199605631-01(15119)/ 2003, C.P. R. Saavedra (Consejo de Estado 18 de Septiembre de 2003).

XVIII. CE, s3, sentencia 30802/2006, C.P. A. Hernández. (Consejo de Estado 30 de noviembre de 2006).

XIX. CE, s3, rad. 25000-23-26-000-200100072-01(31838)/2007, C.P. R. Correa (Consejo de Estado 18 de Julio de 2007).

XX. CE, s3， 25000-23-26-000-2006-0206201(34460)/2009, C.P. M. Guerrero (Consejo de Estado 26 de Marzo de 2009).

XXI. CE, s3, rad. 25000-23-26-000-199308365-01(14461)/2011, C.P. D. Rojas (Consejo de Estado 25 de Agosto de 2011).

XXII. CE, s3, rad. 25000-23-26-000-199801826-01(24898)/2012, C.P. S. Conto
(Consejo de Estado 29 de Agosto de 2012).

XXIII. CE, s3, rad. 05001-23-25-000-199401059-01(21315)/2012, C.P. D. Rojas (Consejo de Estado 29 de Agosto de 2012).

XXIV. CE, s3, rad. 20001-23-31-000-200001310-01(24217)/2013, C.P. D. Rojas (Consejo de Estado 30 de Enero de 2013).

XXV. CE, s3, rad. 25000-23-26-000-199803066-01(20912)/2014, C.P. D. Rojas (Consejo de Estado 27 de Marzo de 2014).

XXVI. CE, s3, rad. 68001-23-31-000-200202796-01 (41008)/2015, C.P. H. Andrade (Consejo de Estado 29 de Julio de 2015).

XXVII. CE, s3, rad. 25000-23-26-000-200102044-02(33925)/2015, C.P. S. Conto (Consejo de Estado 30 de Julio de 2015).

XXVIII. CE, s3, rad. 25000-23-26-000-200201433-01(33790)/2015, C.P. S. Conto (Consejo de Estado 03 de Septiembre de 2015).

XXIX. CE, s3, rad. 25000-23-26-000-201101090-01(50907)/2016, C.P. M. Velásquez (Consejo de Estado 14 de Septiembre de 2016).

XXX. Colombia. L. 80/1993. Por la cual se expide el Estatuto General de Contratación de la Administración Pública.

XXXI. Colombia. L. 1150/2007. Por medio de la cual se introducen medidas para la eficiencia y la transparencia en la Ley 80 de 1993 y se dictan otras disposiciones generales sobre la contratación con Recursos Públicos.

XXXII. Colombia. L. 1563/2012. Por medio de la cual se expide el Estatuto de Arbitraje Nacional e Internacional y se dictan otras disposiciones.

\section{REFERENCIAS COMPLEMENTARIAS}

XXXIII. Crespo, J. E. (2013). La generación de una justicia privatizada en los contratos estatales desde la óptica del Derecho Administrativo.(tesis de maestría). 
Universidad Nacional de Colombia, Bogotá, Colombia. Recuperado de: https://core.ac.uk/download/pdf/7726965 $\underline{\text { 8.pdf }}$

XXXIV. Rojas, L. E. (2015). Análisis de la normatividad que ha orientado la contratación de obras públicas en colombia desde la ley 80 de 1993 hasta el decreto 1510 DE 2013. (tesis de pregrado). Universidad Militar Nueva Granada, Bogotá, Colombia. 
